
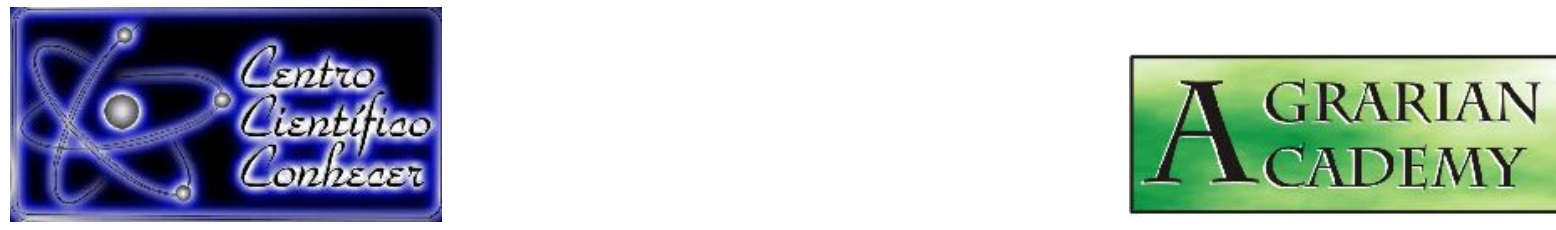

\title{
A INFLUÊNCIA DO AGRONEGÓCIO NA ECONOMIA
}

Ivonete Maria Parreira ${ }^{1}$, Estevão Julio Walburga Keglevich de Buzin ${ }^{2}$, Chrisley Arruda do Nascimento ${ }^{3}$, Cássio Tavares de Souza ${ }^{4}$, Giselly Avelar Parreira Tavares ${ }^{5}$

1- Graduação em História e Medicina veterinária pela UFG, Mestrado pela UFG pesquisadora do Centro Científico Conhecer

2- Biólogo, Dr. em Agronomia pela UFG, pesquisador do Centro Cientifico Conhecer

3- Discente em Direito pelo Centro Universitário Brasília de Goiás - São Luis de Montes Belos - Goiás, Colaborador do Centro Cientifico Conhecer 4-Administração, servidor do IBAMA

5- Administração, servidora do INCRA

Contato: biosfera@innovatio.org.br

Recebido em: 15/06/2021 - Aprovado em: 15/07/2021 - Publicado em: 30/07/2021

DOI: 10.18677/Agrarian_Academy_2021A1

\begin{abstract}
RESUMO
O Brasil é um país agrícola, com extensão continental. A vocação agropecuária prevalece desde os tempos da colonização. O setor do agronegócio domina a economia nacional, influencia os preços de diversos produtos nacionais. As commodities carne e grãos são os maiores geradores de renda e emprego do País. Esta pesquisa teve como objetivo relacionar o aumento dos preços de vários itens que movimentam a economia nacional durante o período de 1994-2021. Os resultados estão apresentados em forma de gráficos que fazem a relação dos aumentos da soja, diesel, dólar, carne bovina e oscilações dos valores da cesta básica e salário mínimo no período estudado. É possível afirmar que as oscilações dos preços das commodities influenciam em toda a cadeia econômica do Brasil.
\end{abstract}

PALAVRAS-CHAVE: Commoditie, Combustíveis, mercado internacional. 


\title{
THE INFLUENCE OF AGRIBUSINESS IN THE ECONOMY
}

\begin{abstract}
Brazil is an agricultural country, with continental extension. The agricultural vocation prevails since the colonization times. The agribusiness sector dominates the national economy, influences the prices of several national products. The meat and grain commodities are the biggest generators of income and employment in the country. This research aimed to relate the increase in the prices of several items that move the national economy during the period 1994-2021. The results are presented in the form of graphs that relate the increases in soy, diesel, dollar, beef and fluctuations in the values of the basic food basket and minimum wage in the period studied. It is possible to affirm that fluctuations in commodity prices influence the entire economic chain in Brazil.
\end{abstract}

KEYWORDS: Commodity, Fuels, international market

\section{INTRODUÇÃO}

A década de 1990 ficou marcada pela transformação econômica ocorrida. O novo modelo de política econômica adotado tinha como objetivo o estabelecimento e a manutenção de taxas de inflação baixas e com estabilidade duradoura. Este modelo estava sendo adotado por diversos países (globalização) demonstrando que as políticas macroeconômicas de curto prazo e as relações teóricas entre as principais variáveis econômicas podiam ser sintetizadas pelo novo consenso macroeconômico (LIMA;MARTINI, 2016).

Ainda de acordo com estes mesmos autores no Brasil houve estímulo ao debate sobre a política econômica nacional, pois grande era a preocupação com a política monetária. O governo brasileiro, então Fernando Henrique Cardoso, seguiu as recomendações do FMI (Fundo Monetário Internacional) e do Banco Mundial, ou seja, a preocupação era manter a estabilização de preços obtida com o Plano Real e realizar reformas na estrutura econômica do País com metas: elevar taxas de juros e política fiscal restritiva.

Para alcançar os objetivos citados o governo teria que seguir uma série de passos: Não é recomendada a política fiscal discricionária, adotar uma política fiscal ágil e flexível, taxa de desemprego deve ser monitorada, o nível de atividade econômica é determinado pela oferta agregada, compatível com uma taxa de desemprego e equilíbrio, é papel do governo intervir no sistema econômico, investimento em educação, redução de desigualdades entre os agentes, incentivar investimentos diretos estrangeiros via incentivos tributários, subsídios e criação de uma força de trabalho qualificada e de maior produtividade, banco central tem que ter credibilidade e definir metas de inflação (LIMA;MARTINI, 2016).

O regime de metas de inflação (RMI) adotado em vários paises na década de 1990, inclusive no Brasil, partia de dois pressupostos: controle da taxa de inflação através de taxas de câmbio e metas monetárias, e preceitos teóricos de que a política monetária não afetaria as variáveis da economia de forma duradoura com a finalidade de obtenção de uma taxa de inflação baixa e estável (PAULA; SARAIVA, 2015). O RMI , como foi operado no Brasil, teve efeitos negativos sobre o nível de produto e renda no País, contribuindo para a economia crescer abaixo do potencial esperado (MODENESI, 2008). 
Libânio (2010) afirmou que entre os anos de 1999-2006, foi possível observar que a política monetária reagiu de forma pró-cíclica e assimétrica a flutuações na atividade econômica. Para Lima e Martini, (2016) é fundamental uma boa coordenação da política econômica e da política macroeconômica, cumprir metas inflacionárias, estabilidade de preços utilizando instrumentos mais amplos de combate à inflação.

Conter a inflação é um fator primordial para a sustentabilidade social e econômica do Brasil. A estabilidade de preços é condição essencial para haver crescimento autossustentado. Maior inflação gera ambiente desfavorável aos investimentos e penaliza as camadas sociais mais pobres, promove a concentração de renda e vale ainda afirmar que os principais bancos do mundo optam pela estabilidade de preços como objetivo da política monetária (BACEN, 2016).

A partir de 2020 é notória a alta dos preços dos bens de consumo de modo geral. A atividade econômica associada à crise da pandemia da Covid-19, aos programas de crédito, pressões de custos decorrentes do aumento dos preços de commodities e taxas de câmbio mais elevadas têm alavancado os preços, principalmente da carne, da soja e do arroz (BACEN, 2020).

Outro fator promotor do aumento de preços é a alta dos combustíveis, visto que no Brasil a logística predominante de transporte é a rodoviária. Caminhões apresentam as desvantagens de transportar volumes pequenos, poluem mais em função da quantidade de caminhões em circulação, gastos elevados de combustíveis, asfaltos de qualidade questionável, tipo de carga e tempo de entrega devido às longas distâncias percorridas (IPEA, 2020).

Historicamente o mercado de trabalho no Brasil resulta da informalização, precariedade, baixas remunerações e desigualdades de diversos gêneros: cor, raça e regiões. Muitos grupos populacionais têm inserção precária no mercado, tornando-os vulneráveis aos altos e baixos dos ciclos econômicos, esta instabilidade gera perdas significativas nas condições de vida da sociedade de baixa renda (IBGE, 2018).

Vários fatores influenciam a oscilação de preços dos alimentos, dentre estes a perda entre a produção, transporte e distribuição. A FAO (Organização das nações Unidas para a alimentação e agricultura) estima que o desperdício gira em torno de mais de um bilhão de toneladas todos os anos em todo o mundo. No Brasil $10 \%$ de todos os alimentos produzidos são perdidos, causando prejuízos econômicos e impactando a produção agropecuária. O governo federal criou o Comitê Técnico de perdas e Desperdício de alimentos com o objetivo de debater estratégias para redução e propor ações para prevenção e atenuação das perdas e desperdício de alimentos produzidos no Brasil (MELO, 2019).

Uma questão bastante discutida no Brasil é o transporte ferroviário. O País é grande exportador de commodities, as dimensões continentais do Brasil desfavorecem o uso rodoviário, aumenta os custos de transportes, o modo ferroviário seria ideal tanto para transporte de cargas quanto de passageiros (BRASIL, 2014). Foram previstos mais de 100 bilhões de reais para a implementação de transporte sobre trilhos até 2017, no entanto até a atualidade várias iniciativas estão estagnadas. O transporte ferroviário tende a ser mais competitivo quando comparado ao rodoviário. Um vagão graneleiro, por exemplo, com capacidade de carga de cem toneladas, é capaz de substituir 3,57 caminhões (BRASIL, 2014). 
A cadeia de custos dos alimentos no Brasil afeta diretamente na cesta básica e no salário mínimo (SM) recebido pelas populações de baixa renda. O salário mínimo vem crescendo há duas décadas, a conjuntura política dos últimos 20 anos favoreceu os reajustes, mesmo sem regras definidas. Em 2011 a lei 12.382 fixou as regras, o SM tem correção baseada no INPC (Índice nacional de preços ao consumidor) e aumento real em relação ao PIB (Produto Interno Bruto). Há controvérsias nesta questão, muitos defendem os aumentos, outros não vêem efeitos na redução da pobreza, sem mencionar que do ponto de vista político significa aumento dos custos públicos (SABOIA; HALLAK NETO, 2018).

Este artigo teve como objetivo realizar uma relação entre os aumentos de preços do dólar, da soja, da carne, do combustível Diesel, do salário mínimo e custo da cesta básica no Brasil do ano de 1994 até o ano de 2021.

\section{MATERIAL E METODOS}

Este trabalho foi efetuado nos meses de abril e maio de 2021 através de levantamento em sites idôneos, tais como: BNDES, IPEA, CONAB, BACEN, ESALQ, INSPER, Centro de Estudos e debates estratégicos da Câmara dos Deputados Federais e Revistas Científicas da área econômica. O projeto abrangeu o período de 1994 a 2021.

Buscaram-se dados de valores das seguintes variáveis: salário mínimo, cesta básica (média), preço da saca de soja (média), preço do diesel (média anual) preço da arroba da carne (média) e valor do dólar comercial no mês de correção do salário mínimo. A partir dos dados numéricos foram feitas correlações dos custos das commodities soja e carne (arroba do boi) que são influenciadas pela oscilação do valor do dólar e aumento do preço do combustível diesel. Outra correlação efetuada foi o aumento do salário mínimo em relação ao dólar e o impacto disto nos custos da cesta básica necessária para o consumo da família brasileira. Os resultados estão apresentados na forma de gráficos.

\section{RESULTADOS E DISCUSSÃO}

A constituição federal promulgada em 1988 estabelece no art. $7^{\circ}$ - Dos direitos e garantias fundamentais, inciso IV- salário mínimo, fixado em lei, nacionalmente unificado, capaz de atender às suas necessidades vitais básicas e às de sua família com moradia, alimentação, educação, saúde, lazer, vestuário, higiene, transporte e previdência social, com reajustes periódicos que the preservem o poder aquisitivo, sendo vedada sua vinculação para qualquer fim (BRASIL, 1988).

Conforme artigo acima mencionado na Constituição Federal o Salário mínimo deve atender as necessidades básicas, sabe-se, no entanto, que os valores praticados ao longo da historia não são capazes de suprir as famílias, a real inflação no Brasil não atinge o reajuste do salário mínimo. Vários fatores econômicos interferem nos aumentos salariais, precarizando a economia das famílias mais vulneráveis.

A desigualdade social cresce cada vez que o poder de compra do brasileiro cai em função das atualizações anuais do salário mínimo. Faz-se necessária à formulação de uma política econômica adequada que reflita melhor a realidade brasileira com o objetivo de aumentar o poder de compra do trabalhador (MESQUITA, 2019).

A comparação de um salário mínimo em dólares encontra-se no quadro 1: 
GRÁFICO 1 - Variação do valor do salário mínimo em dólares de setembro/1994 a janeiro/2021:

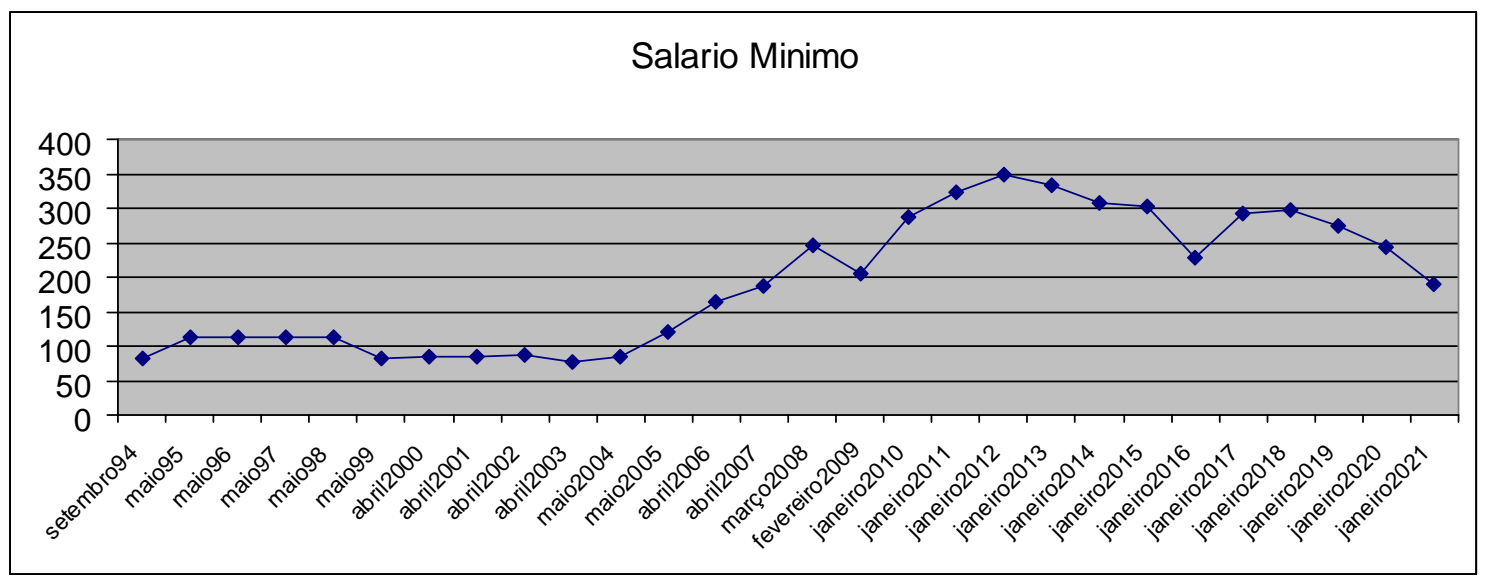

Elaborado pelos autores a partir das fontes

Fonte: valor do salário mínimo; https://audtecgestao.com.br/capa.asp?infoid

Fonte: valor do dólar comercial : http://www.yahii.com.br/dolar.html

No período de 1994 a 2021 o Brasil teve seis presidentes: Itamar Franco (19921995), Fernando Henrique Cardoso (FHC) (1995-2002), Luiz Inácio Lula da silva (20032010), Dilma Rousseff (2011-2016), Michel Temer (2016-2018) e Jair Bolsonaro de 2019 até a atualidade. Pode-se notar no gráfico 1 que em setembro de 1994 o salário mínimo era menor que 100 dólares, estabilizou em pouco mais de 100 dólares a partir de maio/95 indo até maio/98, nota-se então que o presidente $\mathrm{FHC}$ conseguiu certa estabilidade, isto devido à política implantada, criação do Real, controle da inflação, antes em constante alta.

A partir de maio de 1999 o salário mínimo perde poder aquisitivo em relação ao dólar novamente, ficando abaixo dos 100 dólares, houve desvalorização do real. O salário só começou a ter alta em 2005 atingindo o patamar de 250 dólares no ano de 2008. Uma promessa de campanha do então presidente "Lula" era de que o salário mínimo deveria ser de 300 dólares, no mínimo, para garantir segurança ao trabalhador de baixa renda. Em 2009 o dólar subiu fazendo com que o salário mínimo ficasse abaixo de 250 dólares. Entre 2012 e 2013 o salário mínimo atingiu o maior patamar: 350 dólares, caindo novamente a partir desta época. Atualmente oscila um pouco acima de 200 dólares.

Nas últimas duas décadas o Brasil testemunhou um uso muito diverso de instrumentos de política cambial e a moeda brasileira passou por momentos distintos em termos de estabilidade e padrão de flutuação. Destacou-se a fase de janeiro de 2011 a junho de 2013, quando houve um conjunto de medidas e uso mais ativo da política cambial, o uso voltado para os mercados primário, interbancário e de derivativos podem ter contribuído para a maior estabilidade do câmbio (NICÁCIO; ROSSI, 2020).

O gráfico 2 faz um comparativo do poder de compra do salário mínimo em relação ao preço da carne (arroba do boi), uma commoditie com preços ditados pela variação do preço do dólar. Isto ocorre porque a carne produzida no Brasil é voltada para o mercado externo (vendida em dólares e não em reais). 
GRÁFICO 2 - Variação do salário mínimo em comparativo com o preço da arroba do boi de setembro/1994 a janeiro/2021:

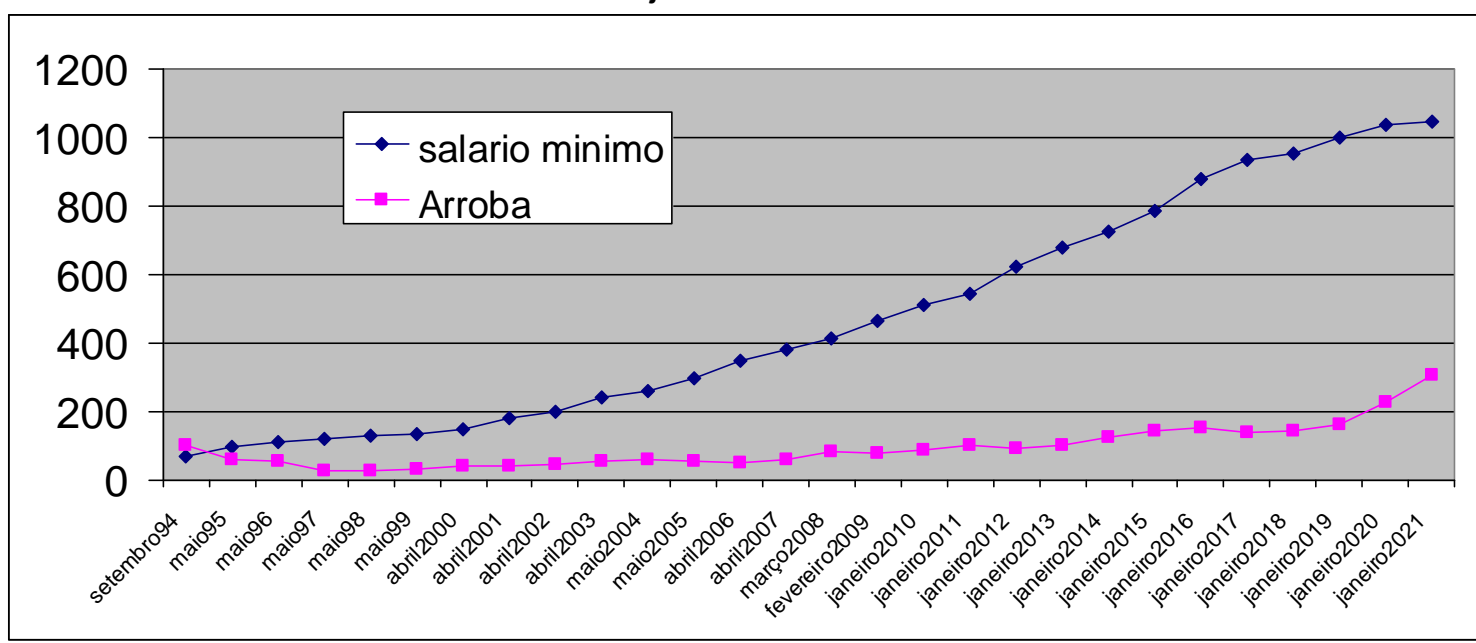

Elaborado pelos autores a partir das fontes

Fonte: valor do salário mínimo; https://audtecgestao.com.br/capa.asp?infoid

Como já foi mencionado em setembro de 1994 o salário mínimo tinha um baixo poder aquisitivo, na época não era suficiente para comprar uma arroba de carne bovina $(15 \mathrm{~kg})$. A partir do governo de $\mathrm{FHC}$ a meta era fornecer proteína de baixo custo à população brasileira, houve grande incentivo para a produção de aves. A meta na época era que o peso de um quilo de carne de ave custasse apenas um real.

Em noticia da folha de São Paulo (1996) afirmavam que o brasileiro estava comendo mais carne bovina. O consumo de frango deu um salto depois da implantação do Plano real, apesar da carne bovina ser a preferida, o preço da carne de aves era mais acessível. A estabilização da economia possibilitou o maior consumo de proteína. $\mathrm{O}$ controle inflacionário permitiu que o brasileiro tivesse mais acesso à carne bovina. $\mathrm{A}$ alta na oferta e estabilização do preço do quilo da carne fez com que o consumo aumentasse paulatinamente durante os primeiros anos do plano real.

À medida que o salário mínimo foi recebendo reajustes acima da inflação passou a ganhar poder de compra e o trabalhador de baixa renda conseguiu ter acesso à cesta básica mais sortida. Conforme a Folha de São Paulo (1996) a elevação dos preços da cesta básica estava ficando menor que os reajustes do salário mínimo.

Atualmente o salário mínimo de $\mathrm{R} \$ 1.100,00$ (2021) pode comprar seis arrobas de carne bovina. Basta ver no gráfico 2 a valorização do SM em relação ao preço da carne. Outros fatores que influenciaram a disponibilidade de carne no mercado interno foi o aumento da produção, expansão da criação para abate, melhoria na questão da reprodução bovina através de novas técnicas, formação de profissionais na área. Todos estes fatores em conjunto permitiram maior oferta por menor preço, mesmo as populações de baixa renda passaram a ter acesso ao consumo de carnes (bovina, suína ou de aves) no cotidiano.

O gráfico 3 demonstra a variação do preço do diesel no período estudado. $\mathrm{O}$ questionamento mais importante a ser feito sobre o diesel é que este é primordial no transporte rodoviário no Brasil. A logística de transporte encarece quando o combustível tem o preço aumentado. Essa questão afeta diretamente a categoria dos 
Caminhoneiros, pois estes realizam o transporte de todo tipo de mercadorias dentro do País.

O preço do diesel tornou-se o principal fator de escolha dos postos pelos caminhoneiros em detrimento da oferta de outras vantagens, visto que conseguir 0 combustível com melhor preço repercute nos ganhos finais do transporte (KAMLOT; WANDERLEY, 2011). Essa mesma realidade de 2011 se repetiu no governo Temer, causando a paralisação dos caminhoneiros em função do alto custo do combustível. Em Julho de 2019, novamente esta categoria veio a público reclamar pelo crescente aumento no preço do diesel.

A relação realizada entre o preço do diesel e do salário mínimo (gráfico 3) é apenas para que o leitor faça um questionamento: o valor dos alimentos que compõe a cesta básica sempre se alteram quando há aumento dos combustíveis, a alegação é que a logística de transporte encareceu, em conseqüência o trabalhador de baixa renda perde poder aquisitivo com o aumento dos alimentos básicos. Abaixo o gráfico 3 demonstra a relação existente entre a alta do diesel com os reajustes do salário mínimo no período estudado.

GRAFICO 3 - Quantidade de litros de diesel que poderiam ser comprados com um salário mínimo e valor do salário mínimo de setembro/1994 a janeiro/2021:

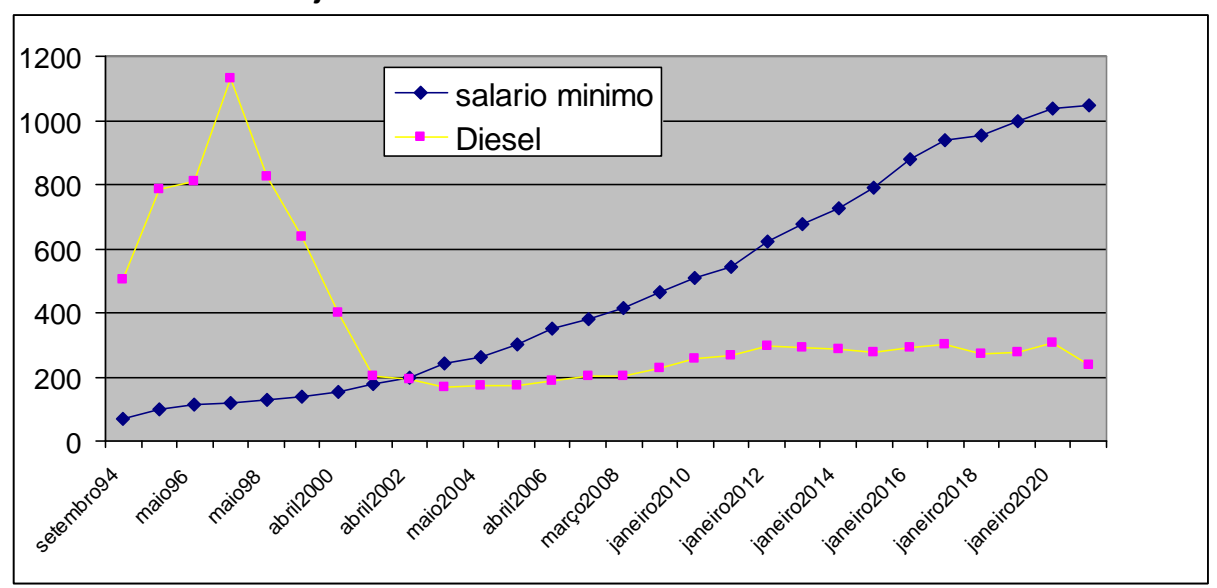

Elaborado pelos autores a partir das fontes

Fonte: valor do salário mínimo; https://audtecgestao.com.br/capa.asp?infoid Fonte: valor do diesel adaptado de Agência Nacional do Petróleo, Gás Natural e Biocombustível (ANP) https://www.gov.br/anp/ptbr/assuntos/precos-e-defesa-da-concorrencia/precos/precos-revenda-e-dedistribuicao-combustiveis/serie-historica-do-levantamento-de-precos

O valor da cesta básica tem variação no Brasil, cada estado pode ter oscilações de preço dos produtos que a compõe. O preço também varia mês a mês. Os dados levantados levaram em consideração estas oscilações, por este fator foi feita uma média dos valores, os quais podem variar para mais ou para menos (desvio padrão).

Conforme Muller et al., (2016) a cesta básica é composta por vários produtos alimentícios, sua composição sofre alterações de região para região, haja vista as especificidades dos produtos consumidos em cada estado do Brasil. 
Estes autores comentam também que o custo da cesta básica influencia 0 salário mínimo, um dos fatores é o comportamento de preços básicos do mercado. Nos cálculos da cesta básica toma-se como base uma família composta por quatro pessoas: dois adultos e duas crianças, o decreto Lei n. 399 determina que a parcela do SM com gastos para a alimentação não podem ter valor inferior ao custo da cesta básica nacional. O resultado apresentado no gráfico 4 foi baseado em valores aproximados.

É possível deduzir com o gráfico 4 que o SM teve maior poder aquisitivo em 2010, quando era possível adquirir 2,5 cestas básicas. De 2018 até a atualidade tem perdido poder de compra, apesar do SM estar sempre sendo corrigido com percentuais acima da inflação anual, não tem conseguido acompanhar a inflação dos bens de consumo. Para os trabalhadores com remuneração acima do SM as perdas são ainda maiores por que os reajustes salariais são feitos com a inflação anual medida pelos índices do governo. Muitos produtos que tiveram alta não são considerados para os cálculos reais da inflação.

Conforme BACEN (2020) é fundamental que a comunicação seja clara para que a política monetária atinja suas metas de forma eficiente. O Banco central do Brasil sempre publica avaliações sobre os fatores econômicos que levam à inflação e apontam os riscos potenciais dessa trajetória. A transparência das informações do BACEN é fundamental para a condução da política econômica do Brasil.

GRÁFICO 4 - Quantidade de cestas básicas que seria possível comprar com um salário mínimo, avaliação no período de setembro/1994 a janeiro/2021:

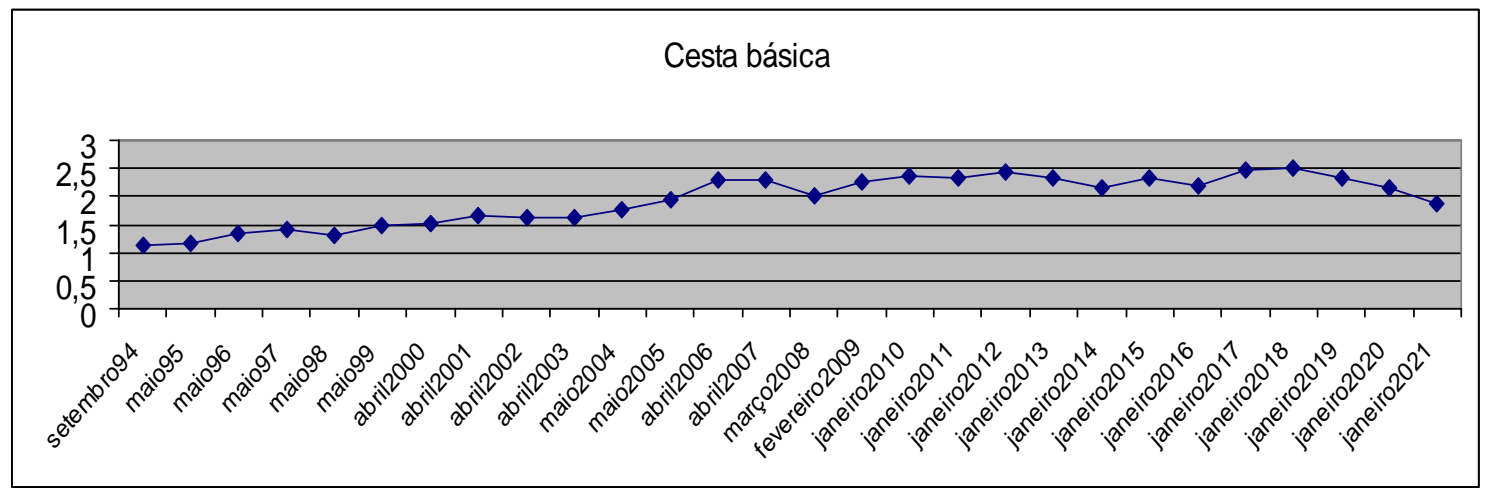

Elaborado pelos autores a partir das fontes

FONTE: Valor da cesta básica adaptado de Departamento Intersindical de Estatística e Estudos socioeconômicos (DIEESE)

https://www.dieese.org.br/sitio/buscaDirigida?comboBuscaDirigida=TEMA\%7Chttp\%3A\%2F\%2 Fwww.dieese.org.br\%2F2012\%2F12\%2Fdieese\%23T356956290 e https://repositorio.ufsc.br/bitstream/handle/123456789/121947/Economia295533.pdf?sequence= 1\&isAllowed=y (PG. 46)

Ainda no gráfico 4 observou-se que nos últimos três anos o SM tem perdido poder de compra da cesta básica, estabelecendo uma rota segura de desvalorização contínua. Neste percurso, o valor de compra voltou aos níveis de 2005.

A soja é uma commoditie e a comercialização deste produto compõe o PIB (Produto Interno Bruto) do Brasil. A relação deste produto com o combustível diesel é AGRARIAN ACADEMY, Centro Científico Conhecer - Jandaia-GO, v.8, n.15; p. 8 
direta. Os maquinários utilizados nas grandes plantações utilizam o diesel, e o custo por hectare plantado é contabilizado. Tanto o transporte de insumos para as lavouras quanto o transporte do grão para a venda são feitos por caminhões movidos a diesel, neste contexto o aumento do combustível influencia no preço final da soja. Os insumos como adubos, defensivos agrícolas e outros também são cotados em dólar.

A exportação de grãos e de carnes são os principais contribuintes do PIB do Brasil. Com o dólar em alta cresceu o interesse do setor agropecuário por produzir estes itens. De acordo com o IBGE (2021) o PIB é um indicador de fluxo de novos bens e serviços finais, produzidos durante um período específico, geralmente dentro de cada ano. Se o País não produzir nada o PIB será nulo. O PIB não é a riqueza de um País, como muitos, equivocadamente, interpretam.

A pressão indica alta recente nos preços das commodities, o real está perdendo poder aquisitivo e a demanda doméstica é forte, implicando em impacto dos programas de transferência de renda. Estão ocorrendo desequilíbrios em algumas cadeias de suprimentos em função da rápida recuperação da demanda por bens. A pandemia contribuiu para o desequilíbrio, em particular no setor de serviços e de produção de embalagens. Os problemas financeiros internos podem ser temporários, ao menos enquanto o regime fiscal for mantido (BACEN, 2020).

O gráfico 5 faz um comparativo entre o preço do diesel e da saca de soja:

GRAFICO 5 - Quantidade de litros de diesel que podia ser comprada com a venda de uma saca de soja de setembro/1994 a janeiro/2021:

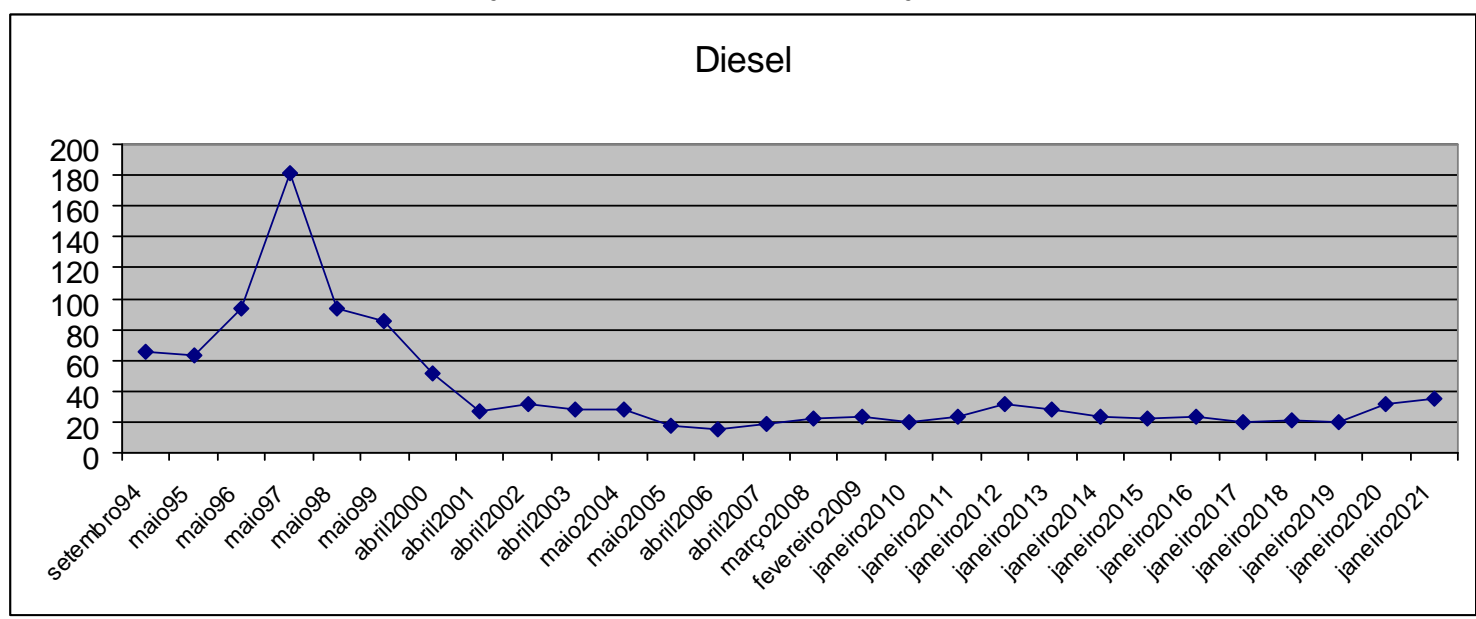

Elaborado pelos autores a partir das fontes

Fonte: valor do diesel adaptado de Agência Nacional do Petróleo, Gás Natural e Biocombustível (ANP) https://www.gov.br/anp/pt-br/assuntos/precos-e-defesa-da-concorrencia/precos/precosrevenda-e-de-distribuicao-combustiveis/serie-historica-do-levantamento-de-precos

A relação do diesel com a soja, como já foi postulado acima, é direta e constante. Ambos têm seus preços aumentados em função das oscilações do preço do dólar e determinam o preço final do produto ao consumidor.

Conforme publicação da Agrofolha (1997) em agosto daquele ano a soja alcançou preço recorde, o que explica o pico no gráfico entre 1997 e 1998, foi um momento de previsão de alta nas safras brasileiras, Argentina e Norte-americana. 
Houve grande incentivo aos produtores no período por ser um momento favorável à investimentos.

Após este momento houve queda vertiginosa de 1998 até 2005. Nos anos seguintes as oscilações foram bem pequenas, com aumentos sucessivos a partir de 2019. Lodi (2019) fez a seguinte análise: O preço da soja é definido internacionalmente, e depende da oferta e demanda global (referência Bolsa de Chicago). A baixa oferta no mundo eleva os preços e a alta oferta faz cair à cotação. É natural que o custo de produção se eleve ao longo do tempo, mas as variações bruscas só acontecem quando ocorre algum fator positivo ou negativo em um dos três maiores produtores de soja do mundo: Estados unidos, Brasil e Argentina.

Ainda segundo esta mesma autora a china é o País que mais consome soja, principalmente dos Estados unidos e do Brasil. Se ocorrer na china algum fator que leve a baixa demanda pela soja o preço mundial cai, um fator recente foi a peste suína africana ocorrida na China, como é sabido a soja é alimento para estes animais, diminuindo o plantel sobrou soja no mercado internacional. $O$ embate político entre Estados Unidos e china favorece a subida de preços da soja brasileira.

A soja para o Brasil é um fator econômico essencial. Maschke et al., (2018) afirmaram que o complexo soja: grão, farelo e óleo formam uma das maiores cadeias agroindustriais do Brasil, o principal destino é o processamento do grão em óleo e proteína. O grão esmagado $80 \%$ é farelo de soja e o restante óleo, ambos produtos altamente consumidos. O farelo vai para a produção de ração para aves, suínos, bovinos e ração para pets. Já o óleo tem ampla utilização na indústria e também na produção do biodiesel. O Brasil é o segundo maior produtor de soja do mundo.

Em 2020 o preço do óleo de soja de uso doméstico subiu 100\%. Essa alta foi estimulada pela demanda aquecida e pela elevação do dólar. Dois fatores influenciaram o aumento do preço: demanda interna da indústria de esmagamento e valorização do dólar frente ao real. O óleo é um produto da cesta básica, neste caso houve um impacto substancial na mesa do trabalhador. Nesta cadeia o atravessador foi quem mais lucrou, o produtor já havia negociado a soja com preços inferiores e terá que obter insumos para a nova safra a preços altos incluindo o diesel. O consumidor na ponta da cadeia, que são as famílias, pagam pelo custo elevado do produto. Resumindo, a indústria compradora do grão obteve e obterá os maiores ganhos neste processo (CANAL RURAL, 2020).

O preço da soja oscila bastante conforme comentado anteriormente, este movimento pode ser visto no gráfico 6 , o comparativo é entre o valor do salário mínimo e o poder de compra deste em relação ao preço da saca de soja. No gráfico, no período de setembro/94 a janeiro/2021 houveram oscilações diversas, independentemente de quem estava à frente da economia do País. Os altos e baixos são explicados pela baixa do preço da soja ou pela perda de poder aquisitivo do SM. As oscilações, para serem explicadas, é necessário verificar todos os fatores de cada período como: valor do dólar, oferta e demanda pelo grão, decisões econômicas, mercado consumidor, financiamentos, aumentos de custos de produção etc.

Os preços da soja registraram oscilações expressivas em 2021, foram influenciadas pelas variações do dólar, pelos relatórios de oferta e demanda, pela lentidão na colheita no Brasil, a necessidade de cumprimento de contratos, em destaque os contratos internacionais, dificuldades logísticas e a paridade de exportação. 
A perspectiva para 2021 é uma colheita recorde (BRASIL, 2021). No gráfico 6 chama a atenção a queda vertiginosa do poder aquisitivo do SM de 2019 até 2021 em relação ao preço da soja.

GRAFICO 6 - Quantidade de sacas de soja que poderia ser adquirida com o valor do salário mínimo de setembro/1994 a janeiro/2021:

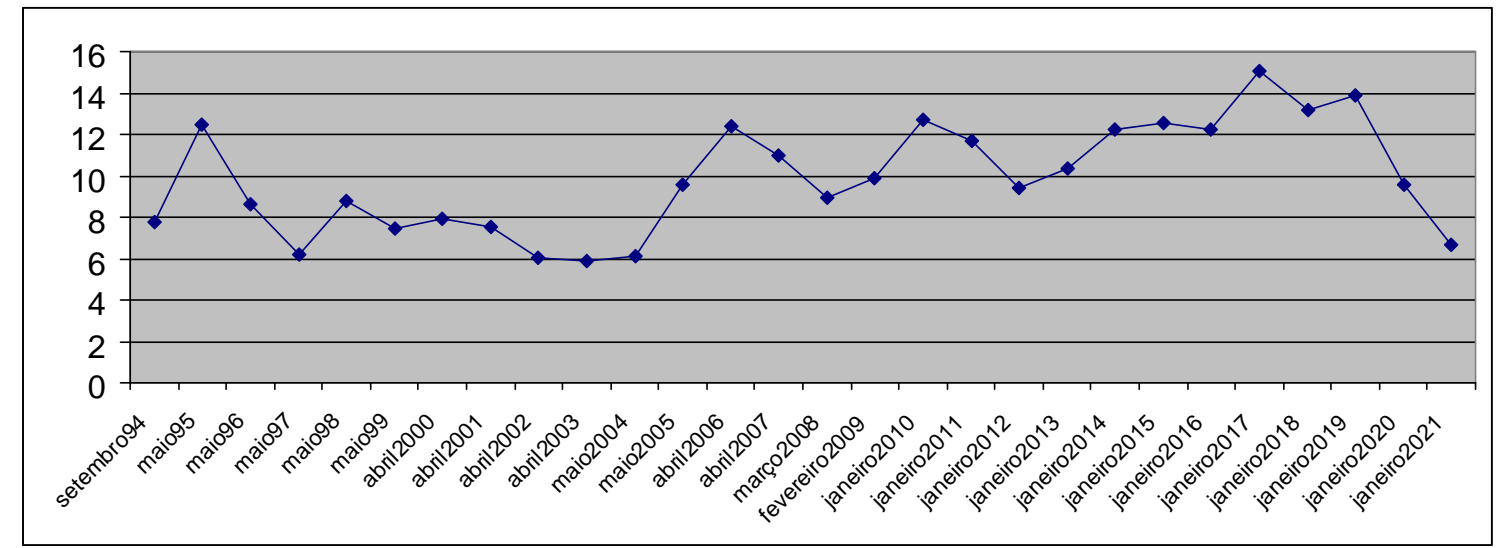

Elaborado pelos autores a partir das fontes

Fonte: valor da saca de soja adaptado de Fonte: CEPEA

https://cepea.esalq.usp.br/br/consultas-ao-banco-de-dados-do-site.aspx

Companhia Nacional de Abastecimento - Conab -http://sisdep.conab.gov.br/precosiagroweb/ https://agenciadenoticias.ibge.gov.br/media/com_mediaibge/arquivos/d0aa621283f9be89365cef dc730c7e36.pdf (pg. 8)

O gráfico 7 apresenta a relação entre o valor do dólar e da média do preço do diesel, é possível deduzir que quase seguiram as mesmas curvas. A relação é fácil de ser explicada, sempre que o real desvaloriza em relação ao dólar os combustíveis sobem, mesmo sendo produtor de petróleo o Brasil não dita o preço, o valor é estipulado pelas decisões monetárias do mercado internacional.

GRAFICO 7 - Dólar comercial e do diesel no período de setembro/1994 a janeiro/2021:

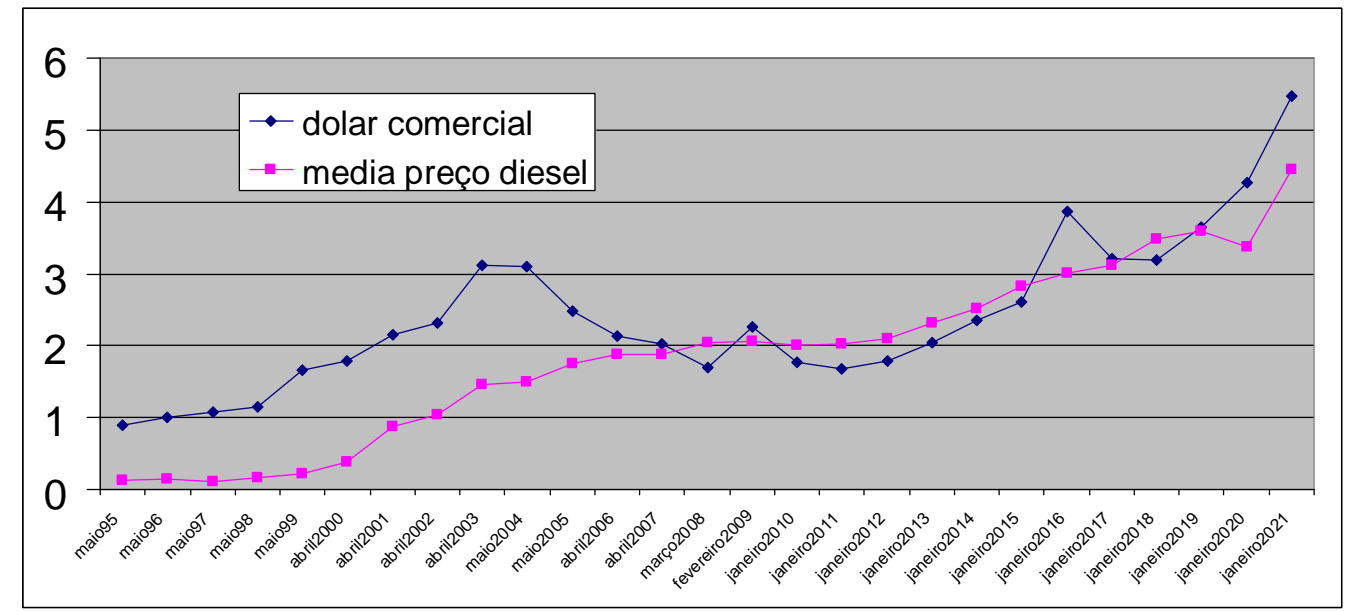

Elaborado pelos autores a partir das fontes

Fonte: valor do dólar comercial : http://www.yahii.com.br/dolar.html 
Não se pode esquecer que o surto global de covid-19 interferiu em todas as atividades do mundo. Um evento extremo e imprevisto como este trouxe mudanças sérias para a economia, as oscilações de preços impactaram o volume de venda de combustíveis e seus preços em escala planetária. Ao ocorrer o comunicado da pandemia houve uma queda brusca da produção, da prestação de serviços e da circulação de pessoas, nestas condições diminuíram os gastos com petróleo e derivados (CNT, 2020). Entretanto, muitas pessoas que utilizavam transporte público optaram pelo transporte individual, mesmo com maior gasto, na expectativa de se protegerem de aglomerações. Este fenômeno fez aumentar a demanda por combustíveis derivados do petróleo.

O petróleo também é uma commoditie geopolítica, os preços são influenciados pelas relações internacionais, estratégias e interesses dos paises produtores. As flutuações de preço em 2020 foram basicamente conduzidas pela crise de instabilidade internacional e a retração econômica generalizada. A Petrobrás desde 2016 adotou uma política de precificação em paridade com a cotação internacional do petróleo, isto somado a taxa de câmbio do Brasil, o preço do diesel A (Diesel A: é fabricado nas refinarias e depois adicionado o biodiesel, impostos, custos e margens de distribuição e revenda) é determinado por esses fatores (CNT, 2020).

No momento há uma discussão generalizada sobre os preços do gás, gasolina e diesel, pois estes produtos têm papel relevante na vida da população e na economia do País. Desde 2016 tem ocorrido instabilidade nos preços destes produtos em função de decisões tomadas pela gestão da Petrobrás em acompanhar a variação do preço no âmbito internacional. Se sobe o valor do barril de petróleo no exterior, automaticamente sobe no mercado interno. As refinarias sobem o valor do câmbio praticado, isto deveria ocorrer apenas em paises que não possuem refinarias, o que não é o caso do Brasil (DIEESE, 2021). Como esta é uma commoditie, seu preço é cotado em dólares. Sempre que ocorrem aumentos este fato é atribuído ao aumento do valor do dólar. Entretanto, quando ocorre a queda do dólar, o valor do combustível não retrai na mesma dimensão.

No qüinqüênio 2016-2020 a produção nacional de petróleo cresceu 18\%, sendo 3,7 milhões barris de petróleo por dia (resultados com o pré-sal), em 2019 o Brasil ocupava o 9ำ maior parque de refino e 9ำ maior consumidor do mundo. O DIEESE destaca ainda que os custos de produção de petróleo e refinados têm caído em razão de melhorias tecnológicas adotadas (DIEESE, 2021).

Segundo o Dieese (2021) o principal motivo pelos preços altos praticados pela Petrobrás foi à paridade internacional feita em 2016, ou seja, o preço é ditado pelo mercado internacional (PPI) que inclui custos de frete de navios, custos internos, transportes e taxas portuárias para cobrir riscos inerentes às operações como variação do câmbio, lucros e tributos.

No inicio de 2021 a situação se agravou com o aumento nos preços do barril no mercado internacional, houve valorização do dólar no mercado interno, a Petrobrás tem repassado os acréscimos para as refinarias. Nos dois primeiros meses de 2021 houve reajuste de 39,5\%, em cinco aumentos no preço do diesel (DIEESE, 2021).

Como já abordado anteriormente, os preços altos dos combustíveis elevaram os preços de vários bens de consumo devido ao modal rodoviário adotado no Brasil. 0 transporte encarece em cadeia tudo o que tem que ser transportado, quem paga por 
toda essa demanda é o consumidor final dos produtos. As diversas classes sociais do Brasil sentem de forma diferente a alta de preços, isto depende da renda familiar, do tipo de negócio que cada cidadão trabalha, da condição financeira antes da crise, das reservas financeiras existentes para momentos de escassez.

Pesquisas evidenciam que as famílias mais ricas poupam mais, enquanto que famílias pobres têm renda menor do que precisariam ao longo do mês. As famílias mais pobres passam por endividamento (crediários, empréstimos) ao invés de conseguirem poupar. Os autores concluíram que a poupança das famílias desde a década de 90 concentra-se em um pequeno número de famílias mais ricas ( $10 \%$ da população) e tem ocorrido uma redução da poupança ao longo dos anos, o que leva à dedução que os donos de capital tem mudado de estratégia, visto que a correção monetária da poupança não neutraliza nem cobre a inflação anual (RODRIGUES et al., 2018).

A proteína de origem animal é alimento essencial ao ser humano por fornecer aminoácidos essenciais ao organismo. O brasileiro tem preferência pela carne "vermelha", ou seja, bovina. Tradicionalmente utiliza-se o churrasco (forma de preparo) para o consumo. O gráfico 8 apresenta a variação do preço do dólar em relação ao preço da carne bovina durante o período setembro/1994 a janeiro/2021. Essa relação foi feita em função da carne ser uma commoditie e ter cotação em dólar no mercado internacional.

GRAFICO 8 - Valor em dólar e da arroba do boi de setembro/1994 a janeiro/2021:

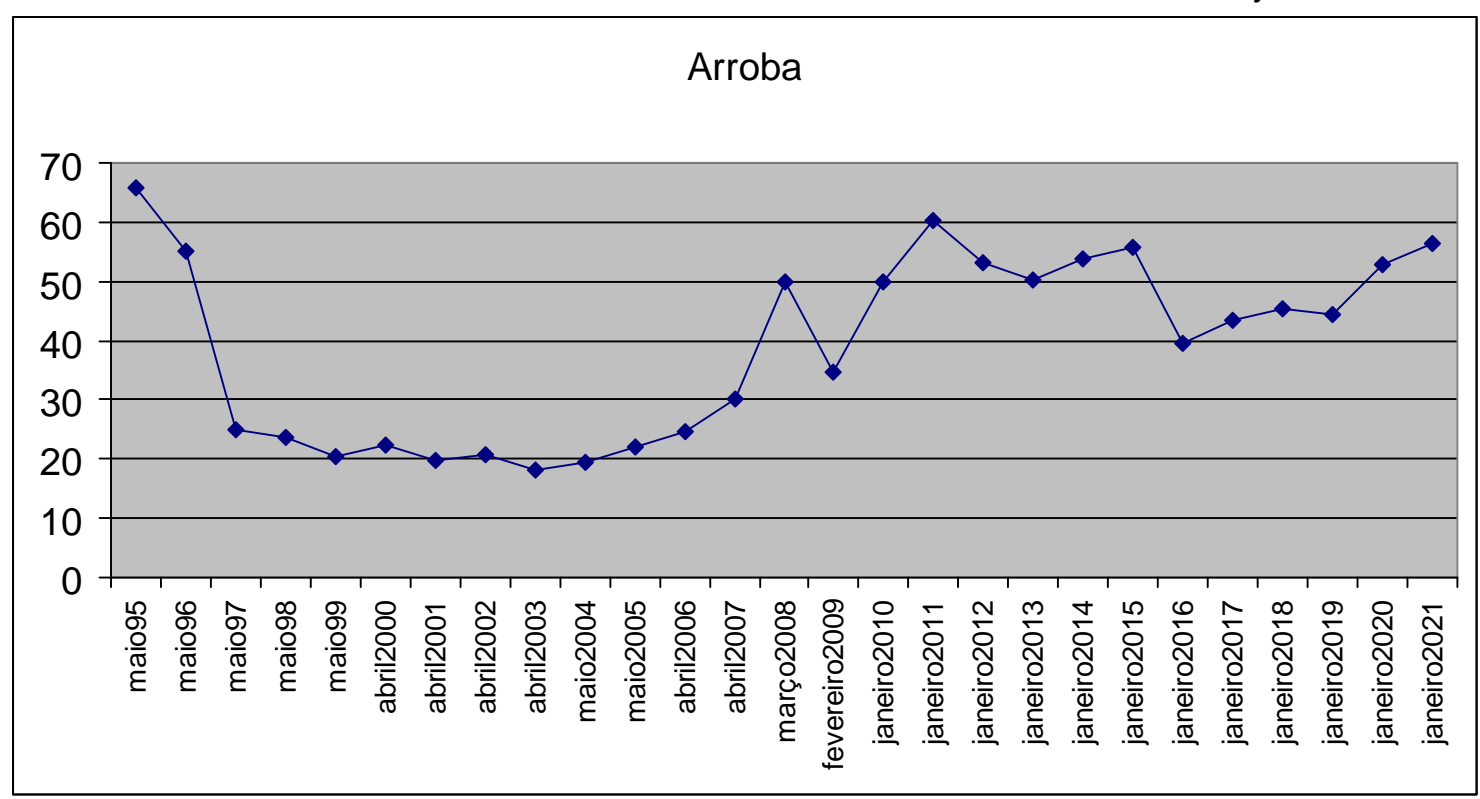

Elaborado pelos autores a partir das fontes

Fonte: valor da arroba do boi adaptado de : https://www.cepea.esalq.usp.br/br/indicador/boigordo.aspx e http://www.faep.com.br/boletim/bi863/bi863pag05.htm

Além do preço do dólar o fator câmbio também é relevante no preço da carne bovina, o dólar acima de 5,70 motivou frigoríficos a atuarem na compra de gado, optando por aqueles que cumprem os requisitos para exportação, principalmente para a China. O preço alto no mercado interno e a crise produzida pela Covid-19 levaram o 
consumidor interno a reduzir o consumo. Os preços cada vez mais altos estão motivando o consumidor para os cortes menos nobres, os bares e restaurantes optam por não fazerem estoque devido ao preço e a necessidade de consumo de proteínas tem se voltado para carne de frango e ovos (CANAL RURAL, 2021).

A arroba do boi está variando em torno de $R \$ 310,00$ (julho/2021). Com a alta do dólar a carne vem se tornando artigo de luxo na mesa dos brasileiros, o consumo caiu 13,7\% em comparação com 2019. De acordo com a CONAB (Companhia Nacional de Abastecimento) a estimativa de consumo por brasileiro seja de 26 quilos ano, este resultado é o menor desde 1996. A certeza é de que o Câmbio tem muita influência no preço da carne já que esta é uma commoditie e o preço é determinado pela oferta e procura do mercado internacional (FERRAZ, 2021).

\section{CONCLUSÕES}

Um conjunto de fatores influencia o preço dos produtos, sendo grande parte originada da economia do agronegócio e suas demandas por insumos e serviços. Entretanto, existem fatores que não podem ser previstos e vão causar severas flutuações nos preços praticados pelo mercado, por exemplo, a pandemia do coronavirus.

\section{REFERÊNCIAS}

AGROFOLHA. Preço bate recorde no Paraná, São Paulo, 5/8/1997. Disponível em https://www1.folha.uol.com.br/fsp/1997/8/05/agrofolha/6.html. Acesso em 22/07/2021.

BACEN - Banco Central do Brasil. Regime de metas para a inflação no Brasil . Informações até junho de 2016.

BACEN - Banco Central do Brasil. Relatório de Inflação, ISSN -1517-6576, v.22, n.4, Dez/2020. Disponível em https://www.bcb.gov.br/content/ri/relatorioinflacao/202012/ri202012p.pdf. Acesso em 13/07/2021.

BRASIL, BNDES - Banco Nacional de Desenvolvimento Social, Transporte sobre trilhos no Brasil: uma perspectiva do material rodante, 2014. Disponível em https://web.bndes.gov.br/bib/jspui/bitstream/1408/3021/2/Transporte\%20sobre\%20trilho s\%20no\%20Brasil.pdf, acesso em 05/07/2021.

BRASIL, Ministério da Economia, Informativo semanal do mercado agropecuário, mar/2021. Disponivel em ww.gov.br/fazenda/pt-br/centrais-deconteudos/publicacoes/conjuntura-economica/agricola/2021/2021_03_12_informativosemanal-bloomberg.pdf. Acesso em 30/06/2021

BRASIL, Constituição Federal do Brasil, 1988. Art.7ํㅡ Dos direitos e garantias fundamentais.

https://www.senado.leg.br/atividade/const/con1988/CON1988_05.10.1988/art_7_.asp, acesso em 12/06/2021

CANAL RURAL. Entenda a alta dos preços do óleo de soja e o que esperar nos próximos meses. Out/2020. Disponivel em 
https://www.canalrural.com.br/programas/informacao/mercado-e-cia/entenda-alta-dosprecos-do-oleo-de-soja-e-o-que-esperar-nos-proximos-meses/

CANAL RURAL.Dólar elevado dá suporte para novas altas do boi gordo. Mar/2021. Disponivel em : https://www.canalrural.com.br/noticias/dolar-elevado-suporte-alta-boigordo/. Acesso em 12/07/2021.

CNT- Confederação nacional de transportes, Economia em foco: preço do diesel. Boletim economia em foco. 2020 Disponivel em https://cdn.cnt.org.br/diretorioVirtualPrd/a072b39a-611b-4e4a-919f-ae542b80a08a.pdf. Acesso em 12/07/2021

DIEESE, Departamento Intersindical de estatísticas e estudos socioeconômicos. Nota técnica n. 251, 0 necessário debate sobre os preços dos combustíveis no Brasil, $\operatorname{mar} / 2021$. https://www.dieese.org.br/notatecnica/2021/notaTec251PrecosCombustiveis/index.html ?page $=$. Acesso em 05/07/2021.

FOLHA DE SÃO PAULO - Carne bovina tem consumo recorde. São Paulo, quintafeira, 24 de outubro de 1996. Disponivel em https://www1.folha.uol.com.br/fsp/1996/10/24/dinheiro/20.html. Acesso em 03/07/2021.

FERRAZ, Y.; Consumo de carne diminui com alta dos preços. Economia, mai/2021. Disponivel em: https://www.dgabc.com.br/Noticia/3723678/consumo-de-carne-bovinadiminui-com-alta-de-precos

IBGE - Instituto Brasileiro de Geografia e Estatística, Estudos \& Pesquisas, Informação demográfica socioeconômica , 39, Síntese de indicadores sociais, uma análise das condições de vida da população brasileira, 2018. Disponível em: https://biblioteca.ibge.gov.br/visualizacao/livros/liv101629.pdf, acesso em 02/07/2021.

IBGE- Instituto Brasileiro de Geografia e Estatística, Produto interno bruto. Disponível em https://www.ibge.gov.br/explica/pib.php. Acesso em 22/07/2021.

IPEA- Instituto de Pesquisa Econômica Aplicada. Logística e transportes no Brasil: uma análise do programa de investimentos 2013-2017 em rodovias e ferrovias. 2020.

KAMLOT, D.; WANDERLEY, R.M.T.C.; Comportamento dos caminhoneiros em postos rodoviários de combustíveis. 2011. Disponível em: file://C:/Users/2020/Downloads/COMPORTAMENTO_DOS_CAMINHONEIROS_EM_P OSTOS_RODOVIAR.pdf

LIBÂNIO, G.; A note on inflation targeting and economic growth in Brazil. Revista de Economia Política, v.30, n.1, p.73-88, 2010. Disponível em https://www.scielo.br/j/rep/a/fphbWKYcYz6fD9MxTVGJVxB/abstract/?lang=en LIMA, A.C.C.; MARTINI, R.A.; O Plano Real e a adoção da política de metas de inflação no Brasil: uma análise baseada no Novo Consenso Macroeconômico. Revista Debate Econômico, v.4, n.1, jan/jun. 2016. 
LODI, A.L.; Quais fatores influenciam os preços da soja? Revista Agropecuária Coopercitrus edição no 391, mai/ 2019. Disponivel em https://www.mercadosagricolas.com.br/inteligencia/quais-fatores-influenciam-o-precoda-soja/. Acesso em 22/07/2021

MASCHKEL, M.C.; OLIVEIRA, J.B.; MATOS, R.; PEREIRA, A.S.; Fatores determinantes da estratégia de preços da soja através da regressão Ridge. VI simpósio da Ciência do Agronegócio. Faculdade de Agronomia, Porto Alegre- RS, out/2018.

MELO, E.V.; Relatório: Perdas e desperdício de alimentos,: estratégias para redução; Centro de Estudos e Debates Estratégicos Consultoria Legislativa, Cadernos de debates 3, 2019. Disponível em : https://www2.camara.leg.br/acamara/estruturaadm/altosestudos/pdf/perdas-e-desperdicio-de-alimentos-no-brasilestrategias-para-reducao. Acesso em 02/07/2021.

MESQUITA, A.J.D.; Salário mínimo: um instrumento de combate à desigualdade. Monografia apresentada para a obtenção do titulo de bacharel Ciência e Economia pela Universidade Federal de Alfenas, 2019.

MODENESI, A.M.; Convenção e rigidez na política monetária: uma estimativa da função de reação do BCB - 2000-2007. Brasília: IPEA, ago/2008. Disponível em http://repositorio.ipea.gov.br/handle/11058/1631. Acesso em 04/07/2021

MULLER, C.F.G.; VOGNACH, A.L.; KRIGER, J. Cesta básica x salário mínimo. La Salle Estrela, v. 1. n. 5. p. $32-107-$ jan/jul 2016. Disponível em: https://www.unilasalle.edu.br/uploads/files/59506b97afee46a21a64e0ca0ef0ceee.pdf. Acesso em 10/07/2021.

NICÁCIO, A.C. ROSSI, P.; Fases da política cambial no Brasil de 1999 a 2018. A Economia em Revista, v. 28, n. 1, p. 1-12, jan./abr. 2020. Disponível em file://C:/Users/2020/Downloads/55057-Texto\%20do\%20artigo-751375213244-1-1020201111.pdf; Acesso em 04/07/2021.

PAULA, L.F.; SARAIVA, P.J.; Novo Consenso Macroeconômico e Regime de Metas de Inflação: algumas implicações para $\circ$ Brasil. Revista Paranaense de Desenvolvimento, Curitiba, v.36, n.128, p.19-32, jan/jun-2015.

RODRIGUES, M.S.; MENEZES FILHO, N. ; KOMATSU, B.K.; Quem poupa no Brasil? Insper, Instituto de ensino e pesquisa, Centro de políticas públicas, n.33, jul/2018. Disponivel em: https://www.insper.edu.br/wp-content/uploads/2018/09/CPP-quempoupa-brasil.pdf. Acesso em 03/07/2021.

SABOIA, J.; HALLAK NETO, J.; Salário mínimo e distribuição de renda no Brasil a partir dos anos 2000. Economia e Sociedade, Campinas, v. 27, n.1 (62), p. 265-285, abr/ 2018. http://dx.doi.org/10.1590/1982-3533.2017v27n1art9. 